\title{
Management and modification procedures for long-term field experiments
}

\author{
P. R. Poulton \\ Soil Science Department, IACR-Rothamsted, Harpenden, Herts., AL5 2JQ, UK. \\ Accepted 16 May 1996.
}

Poulton, P. R. 1996. Management and modification procedures for long-term field experiments. Can. J. Plant Sci. 76: 587-594. Long-term experiments like those at Rothamsted in southeast England offer the best practical means of studying the effects of land management or global change on soil fertility, sustainability of yield or wider environmental issues. For the data from such experiments to be of use, farmers, scientists and policy makers must be certain of their validity. This is best assured by the rigorous management of the experiment, by ensuring that any changes are carefully considered and that all operations are welldocumented. A steady flow of well-interpreted, published data is also essential. This paper gives examples of how the long-term field experiments at Rothamsted have been managed and how modifications have been made to ensure their relevance to modern agriculture.

Key words: Rothamsted, sustainability, long-term experiments, global change

Poulton, P. R. 1996. Techniques de conduite et de modification des expériences de longue durée. Can. J. Plant Sci. 76: 587-594. Les expériences de longue durée, comme celle de Rothamsted dans le sud-est de l'Angleterre, constituent le meilleur moyen pratique d'étudier les effets des méthodes de conduite du sol ou des modifications climatiques à l'échelle planétaire sur la fertilité du sol, sur le maintien des rendements ou sur les grandes questions environnementales. Mais, pour être de quelque utilité pour les agriculteurs, pour les scientifiques ou pour les décideurs ces données doivent avoir démontré indiscutablement leur validité. Cette validité peut être obtenue en premier lieu par la gestion rigoureuse des expériences, de telle sorte que tous les changements soient minutieusement pris en compte et que toutes les opérations soient dúment documentées. Il est essentiel aussi qu'on puisse disposer d'un flot constant de données publiées, judicieusement interprétées. Le mémoire contient des exemples montrant comment les expériences au champ de longue durée de Rothamsted ont été conduites et comment elles ont été modifiées au cours des années pour conserver toutes leur pertinence pour l'agriculture moderne.

Mots clés: Rothamsted, durabilité, expérience de longue durée, modification à l'échelle planétaire

Although long-term experiments have been used for many years, e.g. for studies of soil organic matter (Jenkinson and Rayner 1977), cereal diseases (Glynne 1969) or evaluating PK residues (Johnston 1970), it has only been in more recent years that their value has been more widely appreciated. It is now recognised that questions relating to soil fertility, sustainability of yield, environmental pollution (from both agricultural and non-agricultural sources) and the impacts of management practices or global change can best be answered by using data from long-term experiments [see Poulton (1996) and Johnston (1994) for examples]. Changes in soil-related properties and processes are often (but not always) slow to appear and may be confounded by other factors. Trying to measure change in the short-term can be misleading as there is likely to be considerable year-to-year variability. As a result of this new awareness of the value of long-term experiments, many more scientists are trying to make better use of them, perhaps by re-examining existing data, by making minor or even major changes in treatment or management or simply by making additional measurements. Others may be seeking to start new long-term experiments. Also, scientists are constructing models to be used in predicting the effects of global change. To be successful such models need much more data from long-term experiments, conducted over a wide range of soil types and climatic conditions for validation.
For experiments, and the data from them, to be of value, the user must have confidence in their validity. Only if experiments are managed in a rigorous way can such confidence be assured. In this paper I have drawn on our experiences at Rothamsted to show how long-term experiments have been managed over the years, how they have been modified when necessary, and the methods employed to ensure that the data obtained are of high quality. There are seven "Classical" experiments still continuing of those started by Lawes and Gilbert at Rothamsted between 1843 and 1856. A further 15 "modern" long-term experiments were started between 10 and 95 years ago and still continue. Other examples are taken from experiments which have since stopped.

\section{MANAGEMENT}

\section{Site Tenure and Funding}

Site tenure and funding need to be considered before any planning begins; they may appear obvious but should not be overlooked. Sites owned by an Institute or University offer better security of tenure than sites rented from others. Even so they may in time be threatened by encroaching buildings

Abbreviation: FYM, farmyard manure 
or roads or by pressure to use the site for different experiments.

Funding is a problem for both new and existing experiments. Few funding bodies are willing to give open-ended commitments. Government departments are often regarded as the most appropriate source of money for what is seen as basic research, but they are usually the most reluctant to fund projects for more than 3 to 5 years. The more pressure that can be applied to funding bodies by demonstrating the continued value of these experiments in addressing a wide range of issues, the more likely it is that funds will be forthcoming.

\section{Objectives}

The objectives of any new experiment should be as simple as possible. The Classical experiments at Rothamsted for example were set up to determine the relative importance of the major elements $(\mathrm{N}, \mathrm{P}$ and $\mathrm{K}$ ) known to be present in plants and added to the soil in FYM. Overly complex experiments are likely to be more expensive to maintain and prove less adaptable if and when changes need to be made. Care must be taken to ensure that any effects that the experiment sets out to measure are not confounded by other factors. For example, if the effect of soil organic matter on yield is to be studied, then that yield should not be limited by lack of $P$ or $\mathrm{K}$.

If possible some short-term objectives should be included in any proposed work. These should provide information of immediate value to farmers, advisors or policy makers; an important point when trying to secure funds. It also helps to maintain interest in the experiment at a time when there would otherwise be little to report.

\section{Design}

Many older experiments were not replicated. Large plots (which were a feature of most of the early Rothamsted experiments) give us confidence that effects are real and not an artifact resulting from position in the field. Recent developments in environmental statistics derived, in part, from longterm experiments, increase our confidence in the data (Barnett 1994). Obviously, any new experiment should be statistically sound - this will normally involve a replicated and randomized design and consultation with a statistician.

After deciding on a location, by preliminary survey, and a design, there should be a detailed soil sampling of the site, preferably of each plot, prior to treatments being imposed. Sampling should also include subsoils. The planner of a new experiment should be prepared to abandon the selected site if the soil survey shows an unacceptable degree of soil variability.

Plots should be as large as possible to allow for proper management with farm machinery and to allow for future sub-division if necessary. In arable situations large plots also help to minimize the effect of soil movement; always a potential problem (Sibbesen et al. 1985). Ploughing and/or other cultivations should be along the length of the plot, not across, with soil being turned in one direction one year and the opposite direction the following year. On the Broadbalk Continuous Wheat experiment, which is ploughed every year, the effect of soil movement can be seen by taking a transect across plots receiving different amounts of $\mathrm{P}$. Figure 1 clearly shows the considerable gradient in soil total P content across the $1.5-\mathrm{m}$ paths, extending about $1 \mathrm{~m}$ into each plot $(\mathrm{A}, \mathrm{B}, \mathrm{C})$ but that within the plots there is a region of approximately uniform $P$ content in the central part of each plot. Obviously any soil or crop sampling should be done within this central area. In contrast, on a lighter-textured soil at Woburn where there has been cross cultivation, the gradient extends right across the plots (D, E, F, G) and there is no plateau. In such situations, a complete nutrient balance may not be possible. However the site may still be useful if the current requirement is for comparing crop growth, yield, etc. at different ranges of $P$. In some cases a gradient in a particular soil property may provide a valuable experimental facility.

Where the site is not being cultivated, as in grassland experiments, soil movement is unlikely to be a problem. However, the accurate application of treatments over many years is equally important and is dependent on careful attention to avoid errors. On the Park Grass experiment which started in 1856 the sharp boundaries between plots can be clearly seen. Transects taken across these boundaries show gradients, e.g. in pH status which extend $<0.5 \mathrm{~m}$ into the plot (Fig. 2).

Large plots also allow for subdivision in the future if the need arises; this is discussed later.

\section{On-going Management}

At Rothamsted a committee, the "Working Party for Field Experiments", is responsible for ensuring that the field experiments carried out by the farm, on behalf of the scientific sponsors, are correctly managed. They decide whether changes proposed by the sponsors are acceptable. This prevents any one individual making changes in the experiment which may be detrimental to its long-term integrity.

All field operations carried out by the farm staff are supervised by four experienced people known as "Recorders". They ensure that the plots are correctly marked out (a series of sunken pegs and posts in the field margins provide permanent markers for accurate relocation of the plots each year) and that cultivations, drilling and application of treatments are carried out in accordance to agreed protocol. A detailed record of all operations, e.g. times, amounts applied, etc. is kept. Recorders are also responsible for harvesting and taking samples for yield. The Statistics Department is responsible for the computation of the yields and their statistical analysis; these, together with the details of the field operations are published each year in "Yields of the Field Experiments" (Anonymous 1994).

The experiment sponsors are responsible for taking any crop samples or measurements during the growing season, for soil sampling and for ensuring that the relevant chemical analyses are carried out. They ensure that a database of information for each experiment is maintained and that results are collated, correctly interpreted and published.

All the information from the Classical experiments is gradually being entered on to the Electronic Rothamsted Archive. This will allow easier access to the data and application of computer-based techniques of statistical analyses. It will also include meteorological data which are routinely collected. 


\section{Broadbalk}

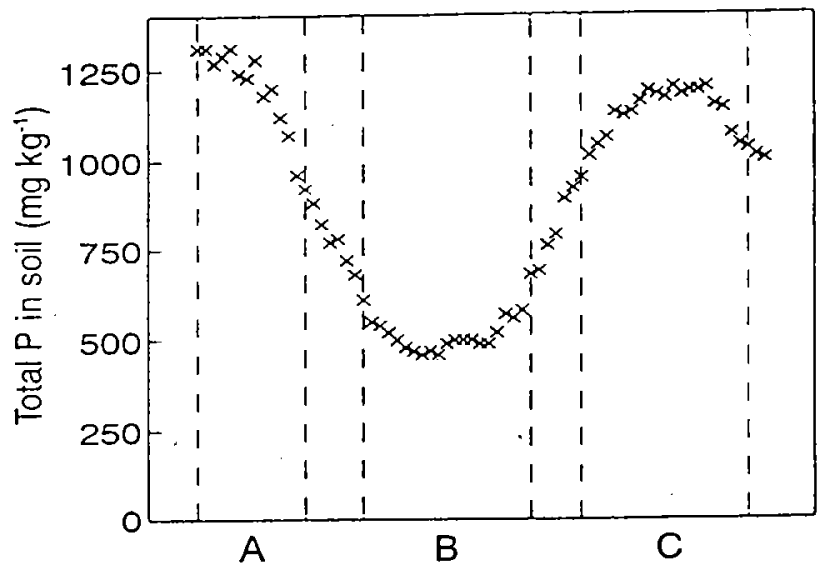

\section{Woburn Market Garden}

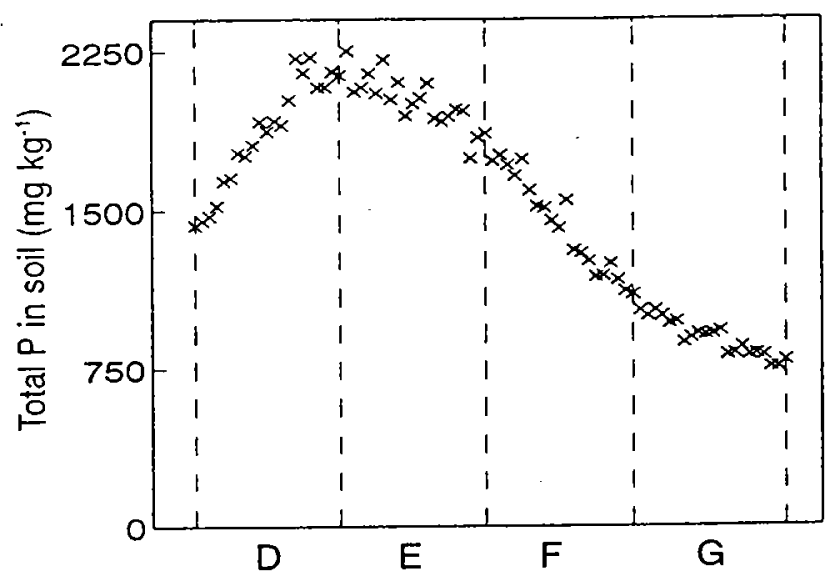

Fig. 1. Total $P$ in the top $23 \mathrm{~cm}$ of soil along a transect across plots given different $P$ treatments. Broadbalk: $A$, FYM $35 \mathrm{t} \mathrm{ha}^{-1} \mathrm{yr}^{-1}$ containing c. $40 \mathrm{~kg} \mathrm{P} ; \mathrm{B}$, unmanured; $\mathrm{C}, \mathrm{PK}$ fertilizers supplying $33 \mathrm{~kg}$ $\mathrm{P} \mathrm{ha}^{-1} \mathrm{yr}^{-1}$; all since 1843. Plot $\mathrm{A}$ is $4 \mathrm{~m}$ wide and is immediately adjacent to another FYM treatment; plots $B$ and $C$ are $6 \mathrm{~m}$ wide. Woburn Market Garden: total amounts of $P, \mathrm{~kg} \mathrm{ha}^{-1}$, applied between 1942 and 1967, E, $13130 \mathrm{~kg}$ in sewage sludge; F, 7720 $\mathrm{kg}$ in FYM; in addition all plots, D E F G, received $1000 \mathrm{~kg} \mathrm{P} \mathrm{ha}{ }^{-1}$ as superphosphate between 1942 and 1984 . Plots are $5.2 \mathrm{~m}$ wide. [Adapted from Leigh et al. (1994).]

\section{Sampling and Analysis}

Crop samples have been taken from the Classical experiments since they began. After drying, an unground portion of plant material was stored in sealed glass bottles or air-tight tins. Other ground subsamples were kept for analysis. At present we continue to store unground samples of grain, straw and herbage from selected plots on Broadbalk (continuous winter wheat, Triticum aestivum L.), Hoosfield (continuous spring barley, Hordeum vulgare L.) and Park Grass (permanent grassland, various grasses, legumes and forbs). A small- er ground sample from a much wider range of treatments and experiments is also kept for analysis and storage.

Soils have been sampled less frequently than crops. In the last century, large samples $(>5 \mathrm{~kg}$ ) were taken from a limited number of points within a plot. After air-drying and subsampling for analysis, these were also stored in sealed bottles. More recently, samples have been taken with semicylindrical augers, bulking a number of cores from each plot. Some experiments are sampled on a regular 5-yr cycle. Others, where modifications are thought likely to result in rapid change, have been sampled every 2 yr; while some may only be sampled every 10 or 20 yr. Samples should be taken accurately to a known depth and should include subsoils, although not necessarily on each occasion. Soil bulk density may change with time as organic matter accumulates or declines. If possible, a correction should be made to allow for any change so that increases or decreases in, for example, total $\mathrm{N}$ content can be accurately determined (Poulton 1995). Samples taken to various depths, together with soil weights, enable this correction to be made. Care needs to be taken in balancing the need for regular sampling and causing unacceptable damage to the plots, especially when sampling subsoils. On some soil types excessive sampling may alter the drainage pattern.

Regular analysis at Rothamsted would include percent $\mathrm{N}$, $\mathrm{P}, \mathrm{K}, \mathrm{Ca}$ and $\mathrm{Mg}$ on crops and percent $\mathrm{N}$ and $\mathrm{C}, \mathrm{pH}$, available $P$ and exchangeable cations on soils. It is also important to keep samples of any fertilizers or organic manures so that inputs can be accurately measured. Most modern inorganic fertilizers are manufactured to a high standard; keeping regular samples of these may not be considered necessary but would be prudent.

The establishment and maintenance of a sample archive is a vital facet of long-term experiments and should be considered as equally important as the experiments themselves. Such an archive can provide material for addressing issues not considered at the start of the experiment; some examples are given later and by Poulton (1996).

Any sampling regime should include regular collection and analysis of bulk precipitation and, where appropriate, drainage water. Rain water was first analysed at Rothamsted in 1853 and drainage water in the 1860 s (Lawes et al. 1881) and has continued since then. Recently, data have been used in studies on acidifying inputs (Goulding and Poulton 1985) and losses of $P$ in drainage (Heckrath 1995).

\section{MODIFICATIONS}

Long-term experiments should not be regarded as unchangeable museum pieces. Indeed, they should be modified to make them as relevant to todays agriculture and environmental concerns as possible but without losing the long-term continuity and integrity of the experiment. However, they should not be changed just to provide answers to short-term problems which could be studied elsewhere. Any change must be well documented. The large number of long-term experiments run by Rothamsted provide examples of different types of change; they fall under three broad headings. 


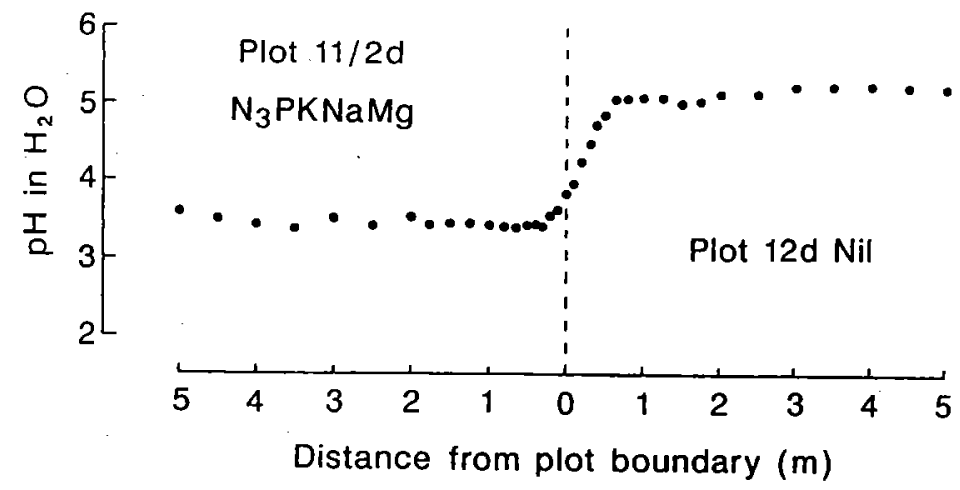

Fig. 2. Park Grass: pH in the top $23 \mathrm{~cm}$ of soil along a transect across the boundary between plots receiving different treatments. $12 \mathrm{~d}$, nil; $11 / 2 \mathrm{~d}, \mathrm{~N}_{3}$ P K Na Mg fertilizers supplying $144 \mathrm{~kg} \mathrm{~N} \mathrm{ha}^{-1} \mathrm{yr}^{-1}$ as ammonium sulphate since 1856 .

\section{Enforced Changes}

These are needed to ensure the continuation of the experiment. The most obvious example of this is acidification, caused by either atmospheric inputs or treatment. At Rothamsted the soil is a silty clay loam (Chromic Luvisol) and although it overlies chalk the topsoil is naturally acid. Some arable soils were heavily chalked in the early 19 th century by digging down to the underlying chalk and spreading this on the surface. Consequently many of the Classical sites had reserves of free $\mathrm{CaCO}_{3}$ when the experiments began and problems with acidity only became apparent 80 or $90 \mathrm{yr}$ later. Soils taken in the 1950 s showed that some plots were becoming progressively more acid. Regular dressings of chalk were introduced to maintain the soil at about $\mathrm{pH} 7.0$. On the sandy soil (Cambic Arenosol) at Woburn, where there is no free $\mathrm{CaCO}_{3}$, problems developed within $15 \mathrm{yr}$ of experiments starting in 1876. Cereal yields declined and although tests of lime were introduced yields never recovered (Johnston 1975). In retrospect yields were probably also affected by cereal cyst nematode (Heterodera avenae), a problem more common on lighter soils, but one which was not appreciated at the time. Separate liming experiments were started at both Rothamsted and Woburn in 1962 (Bolton 1971).

Another example of enforced change was the introduction of regular fallowing on Broadbalk to control weeds. Prior to the First World War, the Classical experiments were weeded by hand or horse-drawn hoe. During and after the war labour became scarce and yields started to decline because of weed competition. In 1926 the experiment was divided into five sections, at right-angles to the 1000 -foot $(320-\mathrm{m})$ length of the plots. One section was fallowed each year to control weeds and yields recovered to their previous levels. Herbicides were introduced in the mid 1950s and the different sections reverted to continuous wheat. Half of one section, however, has never received herbicides, no attempt is made to control weeds other than by fallowing every few years and yields of wheat are much reduced by competition (Garner and Dyke 1969). About 80 species of arable weeds, some rare, have been identified and these represent a valuable source of material; current work includes herbicide resistance in blackgrass (Alopecurus myosuroides) (S. Moss, personal communication).
In a case study of the Rotation $\mathrm{ABC}$ Experiment at Lethbridge, Alberta, Janzen (1995) gave examples of changing management practices. These included a reduction in the number of cultivations necessary for seedbed preparation and weed control following the introduction of routine herbicide applications in 1950 .

\section{Planned Changes}

These are made to ensure that the experiments remain relevant to modern agriculture. Some may involve changing management practices, e.g. the use of tractors instead of horses for ploughing and combine harvesters instead of hand harvesting with scythes. Although this is not a change in the rationale of the experiment it can lead to problems of interpretation. For instance, deeper ploughing by tractor will result in a mixing of subsoil with the previous topsoil. Unless soils from appropriate depths have been taken prior to this happening it can be very difficult to interpret subsequent differences.

On Broadbalk, the introduction of regular fallowing in 1926 led to some interesting research on the effects of the fallow on yields and on wheat bulb fly (Delia coarctata Fall.) (Johnson et al. 1969). Eyespot (Pseudocercesporella herpotrichoides) was first identified in the United Kingdom in 1935, on Broadbalk (Glynne 1969). In 1968, further changes were made on Broadbalk to extend the studies on the effects of soil-borne pests and diseases, particularly take-all (Gaeumannomyces graminis var. tritici) (Etheridge 1969) on yield. Each of the five sections was halved to create $10 \mathrm{sec}$ tions. Some sections stayed in continuous wheat, others went into rotations which compared the yield of wheat after a 2-yr break with that of the continuous wheat. Break crops included field beans (Vicia faba L.) and potatoes (Solanum tuberosum L.). Considering what we now know about soil-borne pests and diseases it is perhaps surprising that continuous cereals have been grown so successfully at Rothamsted. This is not necessarily the case on other soils (e.g. Woburn) and crop rotations may need to be introduced to ensure the continuation of the experiment.

The other major change in 1968 saw the introduction of modern short-strawed wheat varieties. Previously, varieties had remained unchanged for many years in an attempt to relate yield to rainfall. This had proved unsuccessful (Yates 


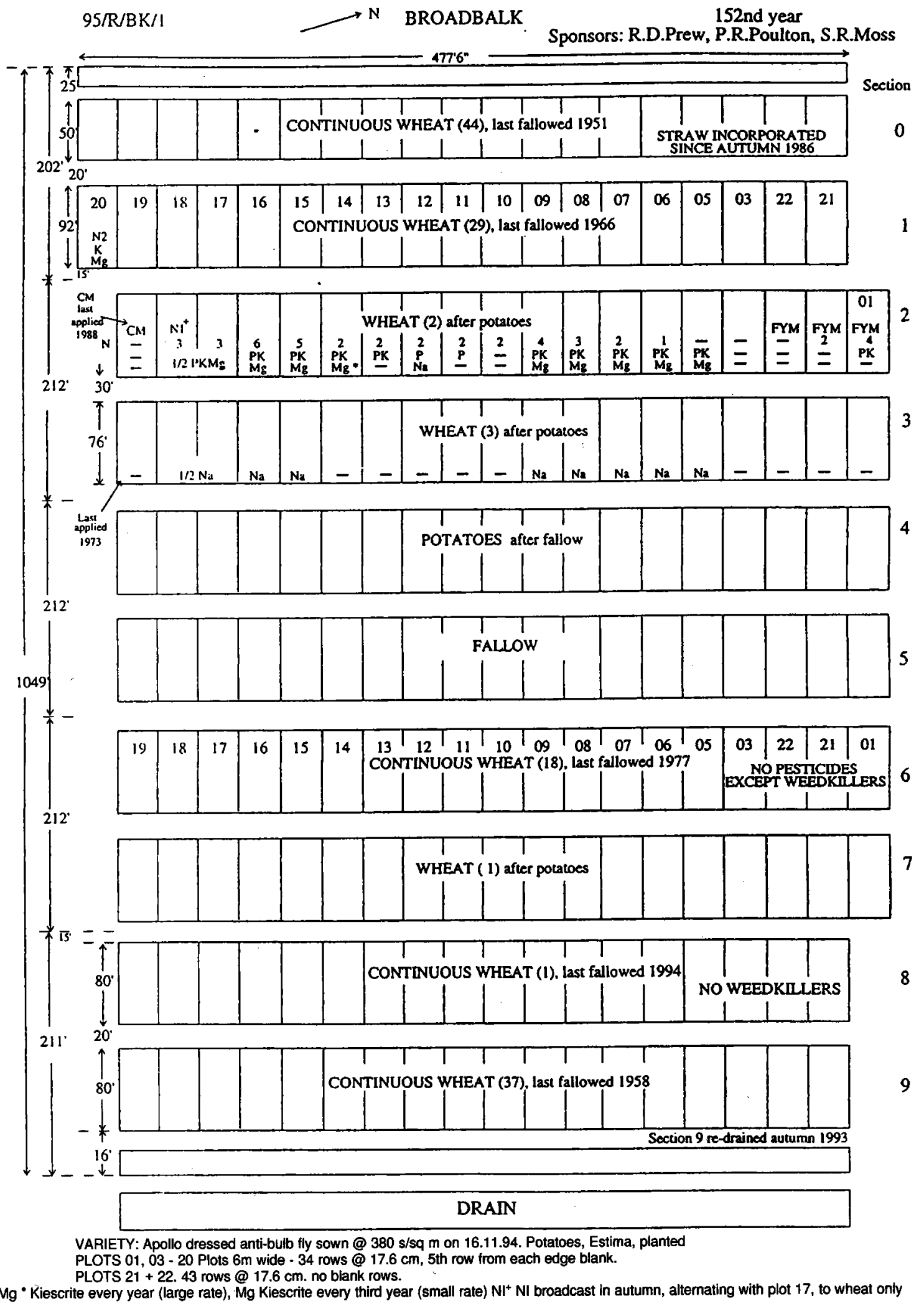

Fig. 3. Plan of the Broadbalk wheat experiment (not to scale). The original plots ran the length of the field and have subsequently been divided to form 10 sections which run across the original strips. The original manure and fertilizer treatments are still applied to the original strips — see text for changes. Sections $0,1,6,8$ and 9: wheat grown continuously (with occasional fallows); section 0: straw incorporated; section 6: no pesticides except weedkiller; section 8 : no weedkiller. Sections $2,3,4,5$ and 7 are in a rotation of fallow, potatoes, wheat, wheat, wheat. 
1969) and it was felt that the experiment would be more pertinent to modern farming by growing a variety that was in general use. We now change the variety regularly, choosing one which will, hopefully, remain on the recommended lists for at least 5 yr.

Other changes in 1968 , or since, have seen the introduction of higher $\mathrm{N}$ rates on some plots, an additional FYM treatment and the introduction of straw incorporation on one section. Since 1979 summer fungicides have been used on all except one section to control foliar diseases. In 1993 the drains on one section which had been installed in 1849 were replaced with modern perforated plastic drainage pipe.

Despite this seemingly long list of changes, the experiment is still recognizably the same and its long-term integrity has not been compromised. Figure 3 shows a field plan for 1995; the 152nd year of the experiment.

As described earlier, increasing acidity caused problems on some arable experiments and regular liming was introduced. On the Park Grass experiment, however, a test of liming has become an integral part of the experiment. Within a few years of the start of the experiment in 1856, plots receiving ammonium sulphate or sodium nitrate, either alone or with $P$ and $K$ fertilizers, showed a dramatic effect in the botanical composition of the sward compared with plots left unfertilized (Lawes and Gilbert 1859). Tests of liming were carried out in the $1880 \mathrm{~s}$ and regular liming was started in 1903 by halving most of the plots. In 1965 it was decided to extend the range of $\mathrm{pH}$ values for each treatment by further division into four subplots. The aim now is to maintain three of the subplots at $\mathrm{pH} \mathrm{7,6}$ or 5 whilst the fourth remains unlimed as a continuation of the original treatment (Thurston et al. 1976). Unlimed subplots receiving $\mathrm{N}$ as ammonium sulphate now have a $\mathrm{pH}$ (in water) as low as 3.2 and are dominated by one or two grass species, compared with the 40 or 50 found on the nil treatment. Although the experiment cannot be regarded as particularly relevant to modern grassland management, it is uniquely valuable to ecologists (Tilman et al. 1994). It is also used in studies of soil acidification (Johnston et al. 1986; Blake et al. 1994).

While most of the experiments have evolved gradually, in others objectives and design have changed very markedly. The "Exhaustion Land" site started in 1852 as an unmanured wheat experiment. Between 1856 and 1875 a second wheat experiment testing $\mathrm{N}, \mathrm{P}$ and $\mathrm{K}$ was conducted. In 1876 wheat was replaced by potatoes and a test of FYM was also included. In 1901, after problems with growing potatoes continuously, probably caused by potato cyst nematode (Heterodera rostochiensis), no further treatments were applied, the site was put into spring barley and although yields were taken for a few years the experiment was effectively stopped. In the 1940 s, however, it was realised that differences in crop growth due to the previous treatments could still be detected. Basal $\mathrm{N}$ was applied and the value of the $\mathrm{P}$ and $\mathrm{K}$ residues tested (Johnston and Poulton 1977). A range of N rates was introduced in 1977 and even $80 \mathrm{yr}$ after the last fertilizer or FYM treatment was applied residues from those dressings still more than doubled yield when adequate $\mathrm{N}$ was given compared with plots never given $\mathrm{P}$ or $\mathrm{K}$. The effects on yield were mainly due to differences in the amounts of readily sol-

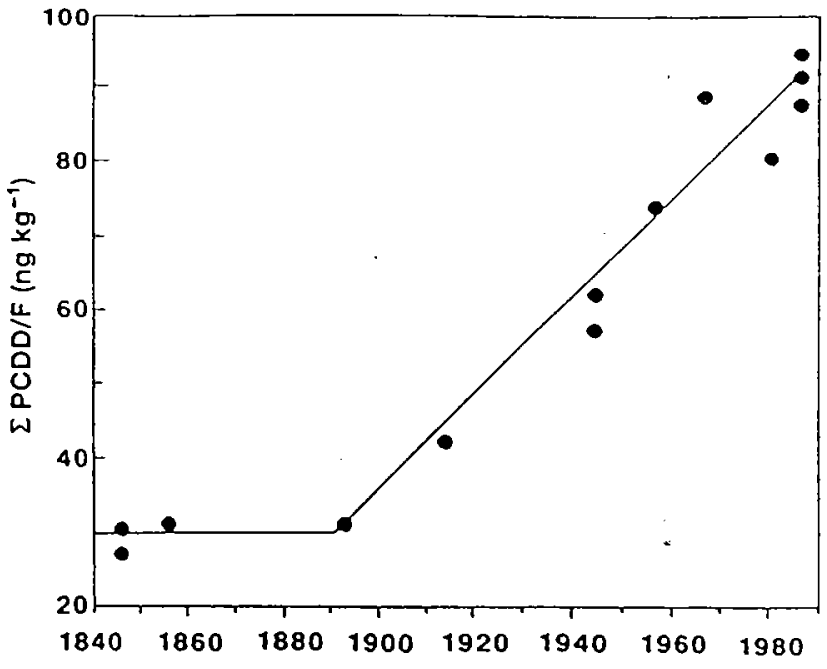

Fig. 4. Trends in the concentration of polychlorinated dibenzo-pdioxin and -furan $\left(\sum \mathrm{PCDD} / \mathrm{F}\right)$ in the top $23 \mathrm{~cm}$ of soil on the unmanured plot of Broadbalk between 1846 and 1986. [Adapted from Kjeller et al. (1991).]

uble $\mathrm{P}$ in the soil ( $\mathrm{P}$ extractable in $0.5 \mathrm{M} \mathrm{NaHCO}_{3}$ at $\mathrm{pH} 8.5$ ), although levels of exchangeable $\mathrm{K}$ were also low.

By 1986 it was thought that little further useful information could be gained by continuing with this "exhaustion" phase of the experiment and it was decided to reintroduce $P$ and $\mathrm{K}$ manuring to see how long it took to increase the amounts of available $P$ and $K$ in the soil to a point where they did not limit yield. In 1986 therefore half of the experiment (20 plots) started to receive basal $\mathrm{K}$ and $\mathrm{N}$ and tested four rates of $P$. In 1992 the remaining half started to receive basal $\mathrm{P}$ and $\mathrm{N}$; the effect of the $\mathrm{K}$ residues is still being measured but rates of fresh $\mathrm{K}$ will eventually be introduced. In 1992 the crop was changed to winter wheat after many years in spring barley. One totally unexpected result of this change was the onset of moderate to severe take-all (R. Gutteridge, personal communication) which has proved of great interest to the plant pathologists.

\section{Additional Measurements}

Long-term experiments of known, well-documented history can provide sites, archived samples and data for investigations into topics never previously considered and for which they were never designed.

For example, Powlson et al. (1986) applied ${ }^{15} \mathrm{~N}$-labelled fertilizer to microplots within the Broadbalk experiment to study $\mathbf{N}$ cycling in the crop:soil system on a site where total $\mathrm{N}$ in the soil had been in equilibrium for more than $100 \mathrm{yr}$. Another example has been recent work on methane oxidation in soil. Since 1992 we have been investigating the effects of land management, form of nitrogen and $\mathrm{pH}$ on the fluxes of methane between soil and atmosphere using various longterm sites (Hütsch et al. 1993, 1994).

Using archived samples it has been possible to measure increases in dioxins in crops and soils (Fig. 4) as a result of atmospheric pollution (Kjeller et al. 1991). In contrast, Fig. 5 


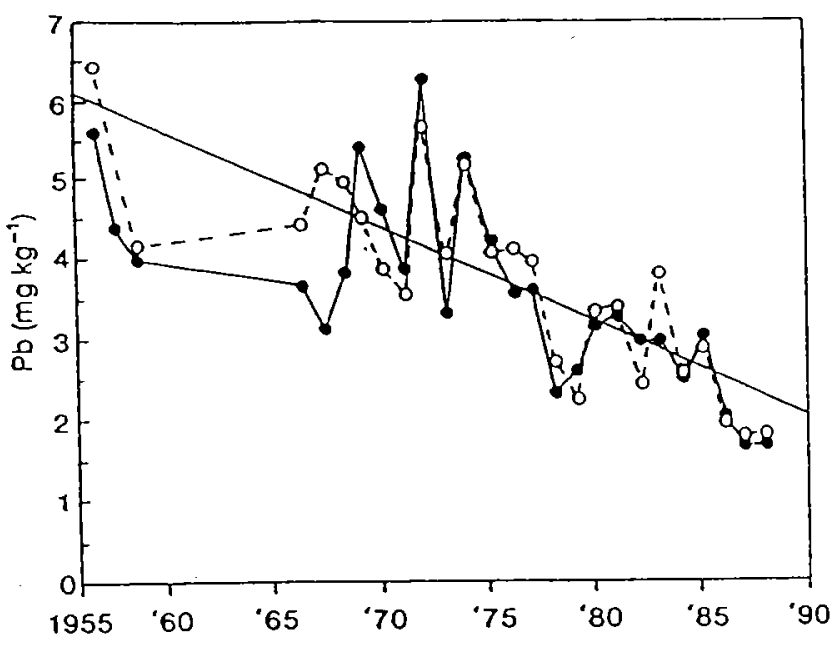

Fig. 5. Lead concentrations in herbage from Park Grass 1956-1988. Soils with fertilizers (O) or FYM (O). [Adapted from Jones et al. (1991).]

shows that lead in herbage has declined in recent years, presumably as a result of the decreasing amounts of lead in petrol (Jones et al. 1991).

Jenkinson has also used archived soil samples extensively in studies of carbon cycling (Jenkinson et al. 1992). This has led to the development of the Rothamsted Carbon Model which simulates the turnover of soil organic matter (Jenkinson 1990). Other models, notably SUNDIAL (a predictive $\mathrm{N}$ use model) developed by Bradbury et al. (1990) have also used data from long-term experiments for construction and validation.

A good example of how a site and archived material can be used for a previously unforseen purpose is provided by the Woburn Market Garden experiment. Started in 1942 to study the effect of different forms of organic matter on yield, it included farmyard manure, compost and sewage sludge treatments which were applied for 20 yr or more. In 1974, when the questions posed at the start of the experiment had been answered (Johnston and Wedderburn 1975), the site was "mothballed" by putting it into grass. Increasing concern in the 1970 s about the contamination of land with heavy metals led to the experiment being revived in 1982. A range of crops was grown and the effects of the heavy metals applied in the sludge between 1942 and 1961 were measured, together with the amounts remaining in the soil. Because crop, soil and manure samples had been kept from the start of the original experiment it was possible to produce a complete balance for a wide range of heavy metals (McGrath 1987; McGrath and Lane 1989). The adverse effects of metals on the soil microbial biomass, and on Rhizobia in particular, have also been considered (Giller and McGrath 1989). Information such as this is proving invaluable as European Community legislation, which seeks to set limits on heavy metals in soil, is being formulated.

Data from a number of long-term experiments in the Philippines, India, the United States and the United Kingdom were used recently in a research study commissioned by the
Rockefeller Foundation. The purpose of this study was to examine the concept of agricultural sustainability and, in particular, to suggest ways in which sustainability could be measured in quantitative terms. The criteria used for choosing sites to participate in this study included the reliability and organization of the data and their continued relevance (Steiner 1995).

\section{CONCLUSIONS}

The examples given above demonstrate the need for flexibility, both in the experiments and in the scientific thinking behind any proposed change. They also clearly show the need for a multidisciplinary approach. As experiments evolve, interactions between chemical and biological processes will mean that the satisfactory interpretation of data by, for example, a soil scientist without referral to a plant pathologist, botanist or statistician is unlikely. After interpretation it is essential that results are widely disseminated at conferences and by publication in quality journals.

Current environmental concerns are such that the need for good quantitative data is perhaps greater now than ever before. In many cases such data can only come from wellmanaged long-term experiments.

\section{ACKNOWLEDGEMENTS}

I thank A. E. Johnston and D. S. Powlson for help in preparing this paper. IACR receives grant-aided support from the Biotechnology and Biological Sciences Research Council of the United Kingdom.

Anonymous. 1994. Yields of the field experiments 1993 Rothamsted Experimental Station, Rothamsted, UK.

Barnett, V. 1994. Statistics and the long-term experiments: past achievements and future challenges. Pages 165-183 in R. A. Leigh and A. E. Johnston, eds. Long-term experiments in agricultural and ecological sciences. CAB International, Wallingford, UK.

Blake, L., Johnston, A. E. and Goulding, K. W. T. 1994. Mobilization of aluminium in soil by acid deposition and its uptake by grass cut for hay - a chemical time bomb. Soil Use Manage. 10: $51-55$.

Bolton, J. 1971. Long-term liming experiments at Rothamsted and Woburn. Rothamsted Exp. Stn. Rep. for 1970, Part 2. 98-112.

Bradbury, N. J., Whitmore, A. P. and Jenkinson, D. S. 1990. A model for calculating the nitrogen requirement of cereals. Abstracts of 1 st Meeting of the European Society of Agronomy, Paris, France. Session 2003.

Etheridge, J. 1969. Take-all on Broadbalk Wheat, 1958-67. Rothamsted Exp. Stn. Rep. for 1968, Part 2: 137-140.

Garner, H. V. and Dyke, G. V. 1969. The Broadbalk yields. Rothamsted Exp. Stn. Rep. for 1968, Part 2. 26-49.

Giller, K. and McGrath, S. P. 1989. Much, metals and microbes. New Sci. 4 (November): 31-32.

Glynne, M. D. 1969. Fungus diseases of wheat on Broadbalk, 1843-1967. Rothamsted Exp. Stn. Rep. for 1968, Part 2. 116-136. Goulding, K. W. T. and Poulton, P. R. 1985. Acid deposition at Rothamsted, Saxmundham and Woburn, 1969-83. Soil Use Manage. 1: 6-8.

Heckrath, G., Brookes, P. C., Poulton, P. R. and Goulding, K. W. T. 1995. Phosphorus leaching from soils containing different $P$ concentrations in the Broadbalk experiment. J. Environ. Qual. 24: 904-910.

Hütsch, B. W., Webster, C. P. and Powlson, D. S. 1993. Long- 
term effects of nitrogen fertilization on methane oxidation in soil of the Broadbalk Wheat experiment. Soil Biol. Biochem. 25(10): 1307-1315.

Hütsch, B. W., Webster, C. P. and Powlson, D. S. 1994. Methane oxidation in soil as affected by land use, $\mathrm{pH}$ and $\mathrm{N}$ fertilization. Soil Biol. Biochem. 26(12): 1613-1622.

Janzen, H. H. 1995. The role of long-term sites in agroecological research: A case study. Can. J. Soil Sci. 75: 123-133.

Jenkinson, D. S. 1990. The tumover of organic carbon and nitrogen in soil. Philos. Trans. R. Soc. Lond. B. 329: 361-368.

Jenkinson, D. S. and Rayner, J. H. 1977. The tumover of soil organic matter in some of the Rothamsted Classical Experiments. Soil Sci. 123: 298-305.

Jenkinson, D. S., Harkness, D. D., Vance, E. D., Adams, D. E. and Harrison, A. F. 1992. Calculating net primary production and annual input of organic matter to soil from the amount and radiocarbon content of soil organic matter. Soil Biol. Biochem. 24: 295-308.

Johnson, C. G., Lofty, J. R. and Cross, D. J. 1969. Insect pests on Broadbalk. Rothamsted Exp. Stn. Rep. for 1968, Part 2. 141-156. Johnston, A. E. 1970. The value of residues from long-period manuring at Rothamsted and Woburn. I. Introduction. Rothamsted Exp. Stn. Rep. for 1969, Part 2. 5-6.

Johnston, A. E. 1975. Experiments made on Stackyard Field, Woburn 1876-1974. I. History of the field and details of the cropping and manuring in the Continuous Wheat and Barley experiments. Rothamsted Exp. Stn. Rep. for 1974, Part 2. 29-44.

Johnston, A. E. 1994. The Rothamsted Classical Experiments. Pages 9-37 in R. A. Leigh and A. E. Johnston, eds. Long-term experiments in agricultural and ecological sciences. CAB International, Wallingford, UK.

Johnston, A. E. and Poulton, P. R. 1977. Yields on the exhaustion land and changes in the NPK contents of the soils due to cropping and manuring, 1852-1975. Rothamsted Exp. Stn. Rep. for 1976, Part 2. 52-85.

Johnston, A. E. and Wedderburn, R. W. M. 1975. The Woburn Market Garden experiment, 1942-69. I. A. history of the experiment, details of treatments and the yields of the crops. Rothamsted Exp. Stn. Rep. for 1974, Part 2. 79-101.

Johnston, A. E., Goulding, K. W. T. and Poulton, P. R. 1986. Soil acidification during more than 100 years under permanent grassland and woodland at Rothamsted. Soil Use Manage. 2: 3-10. Jones, K. C., Symon, C., Taylor, P. J. L., Walsh, J. and Johnston, A. E. 1991. Evidence for a decline in rural herbage lead levels in the UK. Atmos. Environ. 25A: 361-369.

Kjeller, L.-O., Jones, K. C., Johnston, A. E. and Rappe, C. 1991. Increases in the polychlorinated dibenzo-p-dioxin and -furan content of soils and vegetation since the 1840 s. Environ. Sci. Technol. 25: 1619-1627.

Lawes, J. B. and Gilbert, J. H. 1859. Report of experiments with different manures on permanent meadow land. J. R. Agric. Soc. England, 1st Series 19: 552-573; 20: Part II, 228-246; III, 246-272, IV, 398-441
Lawes, J. B., Gilbert, J. H. and Warrington, R. 1881. On the amount and composition of the rain and drainage waters collected at Rothamsted. J. R. Agric. Soc. England 17: 241-279, 311-350.

Leigh, R. A. Prew, R. D. and Johnston, A. E. 1994. The management of long-term agricultural field experiments: procedures and policies evolved from the Rothamsted Classical experiments. Pages 253-268 in R. A. Leigh and A. E. Johnston, eds. Long-term experiments in agricultural and ecological sciences. CAB International, Wallingford, UK.

McGrath, S. P. 1987. Long-term studies of metal transfers following application of sewage sludge. Pages 301-317 in P. J. Coughtrey, M. H. Martin, and M. H. Unsworth, eds. Pollutant transport and fate in ecosystems. Special Publication of the British Ecological Society No. 6. Blackwell Scientific Publications, Oxford, UK.

McGrath, S. P. and Lane, P. W. 1989. An explanation for the apparent losses of metals in a long-term field experiment with sewage sludge. Environ. Pollut. 60: 235-256.

Poulton, P. R. 1995. Geescroft Wilderness, 1883-1995. Pages 385-390 in D. S. Powlson, P. Smith, and J. U. Smith, eds. Evaluation of soil organic matter models using existing long-term data sets. NATO ASI Series I 38, Springer-Verlag, Heidelberg, Germany.

Poulton, P. R. 1996. The Rothamsted long-term experiments: Are they still relevant? Can. J. Soil Sci. 76: 559-571.

Powlson, D. S., Pruden, G., Johnston, A. E. and Jenkinson, D. S. 1986. The nitrogen cycle in the Broadbalk Wheat Experiment recovery and losses of ${ }^{15} \mathrm{~N}$-labelled fertilizer applied in spring and inputs of nitrogen from the atmosphere J. Agric. Sci. (Camb.) 107: 591-609.

Sibbesen, E., Andersen, C. E., Andersen, S. and FlenstedJensen, M. 1985. Soil movement in long-term field experiments as a result of soil cultivation. I. A model for approximating soil movement in one horizontal dimension by repeated tillage. Exp. Agric. 21: 101-107.

Steiner, R. A. 1995. Long-term experiments and their choice for the research study. Pages 15-21 in V. Barnett, R. Payne, and R. Steiner, eds. Agricultural sustainability: Economic, environmental and statistical considerations. John Wiley \& Sons Ltd, Chichester, UK.

Thurston, J. M., Williams, E. D. and Johnston, A. E. 1976. Modern developments in an experiment on permanent grassland started in 1856; effects of fertilizers and lime on botanical composition and soil analyses. Ann. Agron. (Paris) 27(5-6): 1043-1082. Tilman, D., Dodd, M. E., Silvertown, J., Poulton, P. R., Johnston, A. E. and Crawley, M. J. 1994. The Park Grass Experiment: insights from the most long-term ecological study. Pages 287-303 in R. A. Leigh and A. E. Johnston, eds. Long-term experiments in agricultural and ecological sciences. $\mathrm{CAB}$ International Wallingford, UK.

Yates, F. 1969. Investigations into the effects of weather on yields. Rothamsted Exp. Stn. Rep. for 1968, Part 2. 46-49. 